Revista da Associação Nacional dos

Programas de Pós-Graduação em Comunicação

(e) compós

www.compos.org.br

\title{
The invisible reality show: a intervenção performática urbana na produção e recepção do espaço contemporâneo
}

\author{
Fernanda Gomes ${ }^{1}$
}

Resumo: As propostas performáticas que realizam intervenções em espaços públicos, também chamadas de site-specific performances, podem levantar diversas questões e este artigo aborda algumas delas. A partir de perspectivas artísticas, sociológicas, culturais e geográficas, as intervenções e as performances urbanas são localizadas no cenário artístico e na produção do espaço contemporâneo. O artigo parte da experiência do grupo dinamarquês Udflugt, que esteve no Rio de Janeiro apresentando processos e metodologias que fazem parte de sua proposta de trabalho $e$ que surgiram após a criação do conceito The invisible reality show. Pretende-se, então, estabelecer relações entre mudanças perceptivas do espaço cotidiano, processos de sociabilidade $e$ a experiência artística no contexto urbano.

Palavras chave: Performance, recepção, produção do espaço.

\begin{abstract}
The performance intentions that bring interventions to public spaces - site-specific performances - can raise several issues and this article is willing to debate some of them. From the artistic, sociological, cultural and geographic perspectives, the urban interventions and performances take place in the artistic scenario and in the development of contemporary space. This article starts from the experience of the Danish group Udflugt, which has been in Rio de Janeiro to present the methodologies and processes arising after the birth of the concept of "The invisible reality show" and that are used in their work. Through this article we intend to make connections between the perceptive changes of the daily space, the processes of sociability and the artistic experience in the urban context.
\end{abstract}

Key words: Performance, reception, development of space.

Resumé: Les propositions performatiques que réalisent dans les espaces publiques, que aussi s appellent pour site-specific performance, peuvent lever a plus de question et cet article va aborder quelqu uns. Avec la base de las perspectives artistiques, sociologiques, culturalistes et géographiques, l interventions e las performances urbaines sont localise dans le cadre artistique et dans la production de l'espace contemporain.

L ‘article part de l'expérience du groupe danois Udflugt, qui vint dan Rio de Janeiro pour présenter procès et méthodologies que sont pièces de ses propositions de travail et que surgirent après le concept The invisible reality show. Cet article a l'intention, alors, de faire relations entre changements perceptives de l'espace quotidien, procès de sociabilité et l'expérience artistique dans le contexte urbain.

Mots-clés: Performance, reception, production de l'espace.

Resumen: Las propuestas performáticas que hacen intervenciones en espacios públicos - sitespecific performances - llevan a algunas cuestiones abordadas en este artículo. A partir de perspectivas artísticas, sociológicas, culturales y geográficas, las intervenciones y las performances urbanas encuentran su lugar en el escenario artístico y en la producción del espacio contemporáneo. Este artículo parte de la experiencia del grupo dinamarqués Udflugt, que ha presentando en Rio de Janeiro procesos y metodologías que hacen parte de su propuesta de trabajo y que han surgido con la creación del concepto The invisible reality show. Pretendiese, entonces, establecer relaciones entre cambios perceptivos del espacio cotidiano, procesos de sociabilidad y la experiencia artística en el contexto urbano.

Palabras clave: Performance, recepción, producción del espacio. 


\section{Introdução}

The Invisible Reality Show é uma proposta de experimentações em viagens performáticas pelos espaços urbanos, desenvolvidas pelo grupo dinamarquês Udflugt ${ }^{2}$, que prepara trajetórias estimulantes para os sentidos e o intelecto. Suas obras resultam de trabalhos de pesquisa e percepção sistemática dos espaços e se apresentam como sitespecific performances que oferecem ao público um papel alternativo de observador e participante. "Uma performance interativa, um experimento social, uma pesquisa séria, uma excursão virtual?” Segundo a performer Vera Maeder, The Invisible Reality Show faz a performance emergir na mente do expectador, deixando-o aberto para experiências múltiplas, pessoais e exclusivas. Uma mistura de arte visual, princípios interativos, experiências sensoriais e sinestésicas.

No trabalho do grupo Udflugt, a realidade cotidiana do lugar é usada como um cenário performático e permite que acasos próprios dos movimentos do espaço urbano interajam com atos intencionais. Cada site-specific performance é única e estabelece um diálogo específico com cada ambiente escolhido. O conceito foi criado por Vera Maeder, durante suas pesquisas no Danish Arts Concil em 2005, com grande colaboração do artista Eero Tapio Vuori ${ }^{3}$. Atualmente o grupo Udflugt é formado por Vera Maeder, Jacob Langaa-Sennek e Kristofer Krarup.

\section{The invisible reality show no Rio de Janeiro}

Era a primeira vez do grupo Udflugt no Brasil. Ao chegar no Rio de Janeiro, com a missão de definir o local para suas intervenções performáticas, o grupo procurou, segundo suas demandas, "um lugar vivo, movimentado, cheio de ritmos, contrastes e manifestações culturais”. Em um primeiro momento, o grupo fez um mapeamento rápido, quase intuitivo, levado apenas por apelos instantâneos e manifestações visuais contundentes. Após esta “busca perceptiva” pelo Rio de Janeiro, a região da Lapa foi escolhida. A partir daí, seus integrantes passaram a freqüentar a região dia e noite, juntamente com os participantes do workshop oferecido pelo grupo, fazendo parte de sua dinâmica de trabalho. 
Para o grupo, era fundamental o processo de pesquisa e criação coletiva com os próprios moradores da cidade, que poderiam estabelecer um acesso mais fluido e direto às ruas, pessoas e fenômenos do contexto da Lapa. Após duas semanas de convivência e práticas experimentais e a partir de sua metodologia de trabalho, que busca estabelecer diferentes formas de percepção dos espaços, o grupo formado pelos performers e os participantes da oficina criou, preparou e sequenciou os fragmentos que fariam parte desta viagem performática pelo Rio de Janeiro ${ }^{4}$.

Após retirar a sua entrada em um típico restaurante da Lapa, o “espectador” começa sua experiência, guiado por alguns dispositivos. Entre estes dispositivos estão gravações ouvidas pelos fones de um aparelho MP3, bilhetes e orientações dadas pelos performers no decorrer da trajetória. O espectador pode então percorrer, perceber e vivenciar a Lapa de uma maneira inusitada, bem diferente da habitual.

A trajetória criada para a Lapa tem elementos e dinâmicas próprias do lugar, apropriados e retrabalhados para estimularem percepções diferenciadas, através de uma sequenciação de experiências: ser levado por ruelas e becos, deitado em um carro de mão, olhando para o céu; ter os pés lavados, em uma bacia de água, olhando para o lixo; permanecer sentado, em um ponto de ônibus movimentado, enquanto ouve-se pelo aparelho MP3 o som de água caindo; andar de olhos fechados, por espaços contrastantes, sendo guiado por performers; permanecer de olhos fechados, deitado em cima de papelões, no meio de uma praça pública; fugir do som de tiros, ouvidos pelo aparelho MP3, na rua mais movimentada da Lapa; descobrir os segredos de uma rua, habitada por famílias, travestis, músicos e traficantes, olhando por frestas nos muros, janelas e portas entreabertas.

Grande parte dos espectadores que passaram pela viagem performática definiu a experiência como uma redescoberta da Lapa, seus sons, cheiros, imagens e ambientes, enquanto interagia com os performers, os freqüentadores do lugar e com a narrativa criada especialmente para The invisible reality show no Rio de Janeiro. Ao final, cada um teve sua própria experiência, a partir de uma reconstrução mental do espaço e de um despertar individual de sensações. 
Revista da Associação Nacional dos

Programas de Pós-Graduação em Comunicação

\section{e compós}

www.compos.org.br

Todos os momentos dessa viagem performática foram criados com fragmentos e práticas que fazem parte do cotidiano da Lapa, em sintonia com seus ritmos, mas criando uma nova perspectiva daquele espaço, que se tornou familiar e estranho ao mesmo tempo, tanto para os espectadores, quanto para os freqüentadores e, principalmente, para o grupo Udflugt, que não esperava chegar a um nível tão intenso de sociabilidade e de trocas naquele contexto.

\section{Site-Specific Art}

Segundo Nick Kaye (2000), a principal questão colocada pelas obras de Sitespecific art surge a partir das trocas entre o trabalho artístico e os lugares nos quais seus significados são definidos. Se a idéia de que os significados das ações e eventos são afetados pelo espaço, ou pela situação da qual eles fazem parte, então o trabalho artístico também poderá ser definido pela sua relação com o lugar e o contexto. Refletindo sobre essa noção, a teoria semiótica propõe que a leitura esteja implicada em um posicionamento. Ler um signo é reconhecer seu lugar no sistema semiótico.

Um trabalho de site-specific art pode ser articulado e definido através de suas propriedades, qualidades e significados, produzidos em relações específicas com objetos, eventos e posições. Nesse contexto, a conexão entre a performance e o lugar é resultado de estratégias de ocupação e de produção do espaço. A ênfase na performance se dá pela reconsideração da operação da linguagem na relação entre posicionamento e lugar, ou seja, no processo de descoberta dos potenciais performáticos do próprio lugar.

Michel de Certau (1997) busca relacionar “lugar” e “espaço”, adotando a distinção semiótica que Saussure criou entre a língua e a prática, ou seja, a distinção entre a linguagem e a expressão. Dessa forma, Certau propõe que o espaço é o "lugar praticado”. O lugar é o acordo que se estabelece entre os elementos que são distribuídos em relações de coexistência. O espaço ocorre como efeito produzido pelas operações que o definem e que o situam. Na relação com o lugar, o espaço é como a palavra quando é falada, situada no presente e modificada pelas transformações causadas por sucessivos contextos. O espaço, como o "lugar praticado", admite a imprevisibilidade. Se o espaço é como a palavra quando é falada, então um lugar poderá ser redefinido em sucessivos, múltiplos e 
Revista da Associação Nacional dos

Programas de Pós-Graduação em Comunicação

\section{(e) compós}

www.compos.org.br

até irreconciliáveis espaços. Para Certau, a cidade está sempre nessa condição transitória, produzindo uma consciência de performance contínua do lugar. O ato de mover-se pela cidade já cria uma sensação de experiência social transitória.

A especificidade de um lugar pode tomar forma a partir das relações entre as práticas espaciais. Lefebvre apontou o vivido, o percebido e o imaginado. Nick Kaye propôs uma incursão nas intercessões entre o espaço ambientado, o espaço literal e o espaço real. Quais são as fronteiras? E como o trabalho artístico pode explorá-las? As inter-relações dessas ordens espaciais privilegiam a posição do espectador e seu processo de recepção. E é a paisagem urbana que oferece uma profusão e uma complexidade de signos e espaços onde as condições de recepção e leitura podem ser trabalhadas de inúmeras formas.

A site-specific art parece apresentar uma resposta contemporânea às indagações de David Harvey sobre a representação e a espacialização. O autor questiona "como podem espacializações em geral, e práticas estéticas em particular, representar o fluxo e a mudança, especialmente se estes últimos forem considerados verdades essenciais a serem transmitidas? (HARVEY,1994, p.191)”

Movimentos anteriores buscaram responder a estes questionamentos, implícitos no desenvolvimento das práticas artísticas espaciais. O futurismo buscou moldar o espaço para representar a velocidade e o movimento. Considerando a arte como algo efêmero, os dadaístas renunciaram a toda espacialização permanente, buscando a eternidade de seus eventos através de ações revolucionárias. A combinação de filme e música poderia se oferecer como um poderoso antídoto para a passividade típica da arte e da arquitetura, mas, segundo Harvey, o próprio confinamento do filme a uma tela sem profundidade e à sala de cinema é um lembrete de que ele também se encontra restrito no espaço.

\section{A Teoria da Experimance}

O conceito Experimance foi criado pelo artista Eero-Tapio Vuori ${ }^{5}$ - um dos colaboradores do Grupo Udflugt - e surgiu de sua busca por uma fusão entre a experiência e a performance. O artista começou a questionar o papel do espectador e sua presença no processo de recepção da obra. Suas questões estavam sempre relacionadas à relação entre 
Revista da Associação Nacional dos

Programas de Pós-Graduação em Comunicação

\section{(e) compós}

www.compos.org.br

espectador e performer, entre espectador e espectador e entre olhares e ações durante o acontecimento performático.

Segundo Eero-Tapio Vuori (2004), muito foi escrito sobre a presença do ator, mas muito pouco sobre a presença do espectador. Seu objetivo passou a ser buscar um reposicionamento do espectador e transformar sua consciência em um palco, onde a performance ganharia novos sentidos, a partir de sua relação com os acontecimentos do entorno. Essas idéias são bem ilustradas na obra Gateless Gate (1999) que, segundo o artista, consiste em uma performance sem atores. O espectador permanece sentado na frente de um estacionamento durante uma hora e observa a rua, percebendo os acontecimentos cotidianos. E só. Não há atores, somente a sugestão: veja o que acontece à sua frente. Para o artista a experiência funcionou, após a observação das reações dos espectadores, que ficaram intrigados ${ }^{6}$. A teoria de Eero é que durante o tempo em que o espectador está sentado diante da rua, sua consciência passa por uma mudança. O que o levou a se perguntar se a performance e a arte podem ser, efetivamente, mudanças de consciência.

Para Eero, quando assistimos à performance, operamos em outra estratégia fenomenológica. Como nós vemos É o que nós vemos. Estes pensamentos tiveram um grande impacto em suas obras posteriores e o artista começou a se perguntar se alguns conceitos, como espectador e performance precisariam ser reavaliados. Ele começou então a fazer alguns experimentos e pesquisas, a maioria no espaço urbano cotidiano.

A Experimance se diferencia da performance e do evento teatral por ser extremamente individual, ou seja, o objetivo principal é que a experiência esteja intimamente ligada à percepção de cada espectador e à forma como ele se relaciona com os acontecimentos e estratégias criados para ele. Quando a recepção coletiva é removida, a percepção individual passa a ser mais valorizada e o espectador se torna o principal ponto de referência da obra. Fica cada vez mais difícil separar os estímulos exteriores dos sentimentos internos, acontecendo uma verdadeira imersão física no espaço.

O tradicional lugar de recepção do espectador do teatro ou do cinema é a platéia, geralmente escura, na qual ele fica parado, enquanto olha para a mesma direção daqueles que estão à sua volta. Na Experimance, o espectador está em movimento - andando, 
Revista da Associação Nacional dos

Programas de Pós-Graduação em Comunicação

\section{e compós}

www.compos.org.br

esperando, sentando-se, olhando, buscando, levantando-se, andando outra vez - e se torna parte essencial da obra. Ele pode se mover em uma área específica e a obra se movimenta junto com ele. Tudo está focado no espectador - ele é o nexo de toda a ação.

Outro aspecto fundamental da Experimance é a imersão fenomenológica. Normalmente o teatro é baseado na separação entre a realidade e o espetáculo, mas na Experimance a coexistência da realidade e do espetáculo é o principal fator. O espectador não consegue distinguir exatamente o acontecimento casual cotidiano do acontecimento performático que o engloba. Ele pode caminhar pela cidade e experimentar simultaneamente duas realidades, a real e a inventada. E na maior parte do tempo ele não consegue encontrar as diferenças. Esta consciência dupla cria um novo tipo de campo fenomenológico em volta do espectador, que passa a receber cada encontro de forma diferenciada. A percepção se amplifica e enche de significados tudo o que acontece, mesmo que de forma mais banal e corriqueira, como pessoas comuns passando, ou um carro com alto-falantes. Toda a cidade se torna um palco ou uma realidade temporária. E o único limite para este tipo de palco é a mente. As experiências espaciais e temporais fragmentadas lembram o interesse de Deleuze por outros tipos de individuação, como “a individuação de uma hora do dia, de uma região, de um clima, de um rio ou de um vento, de um acontecimento (DELEUZE, 1992, p. 38).”

\section{O fazer cotidiano e a experiência}

“A arte existe para que se possa recuperar a sensação de vida; existe para fazer com que as pessoas sintam as coisas, para tornar a pedra pedregosa. O propósito da arte é transmitir a sensação das coisas como elas são percebidas e não como elas são conhecidas"

Certau destaca o cotidiano como permanentemente inventado para permitir o fluxo da vida e aberto à criatividade. A experiência procura integrar o estranho e o familiar, alargando e enriquecendo o que se encontra no limite do real possível. O autor sugere que o andar define o "espaço de enunciação”, evocando uma coleção inumerável de singularidades próprias da cidade, onde caminhos entrecruzados dão sua forma aos lugares. 
Revista da Associação Nacional dos

Programas de Pós-Graduação em Comunicação

\title{
(e) compós
}

www.compos.org.br

Os artistas que buscam se inserir no contexto urbano contemporâneo, também recorrem ao método fenomenológico, elaborando traçados para um caminho que possibilite apresentar o mundo de maneira viva, sempre atentos aos fenômenos empíricos. A principal prática é a de atribuir profundidade ao factual, ao acontecimento, ao fenômeno, àquilo que se mostra, levando a um projeto de investigação que tenta apreender a vida cotidiana a partir da concretude das pequenas coisas.

Quando revividos através de uma experiência estética, comportamentos e significações criados, negociados e legitimados no cotidiano, passam a outros níveis de significação e interação, indo de encontro a um jogo de reconhecimento recíproco e à produção de interpretações e pontos de vistas, constituídos de elementos cognitivos. Segundo Schaeffer:

\begin{abstract}
“A conduta estética é uma estrutura intencional definida pelos seguintes elementos: a) ela comporta uma dimensão cognitiva que não se distingue inteiramente da nossa relação cognitiva 'banal' com o mundo; b) ela está assentada na percepção comum do mundo (e não científica ou reflexiva); é o mundo que 'age' sobre nós, isto é, que nos afeta e nos obriga a ajustar nossas representações a ele; c) quando nos entregamos a uma conduta estética, nossa atividade cognitiva torna-se fonte de prazer; d) aquilo que constitui o objeto de nossa atenção cognitiva é dotado de propriedades que lhe concedemos não através de uma crença ou de um julgamento, mas por meio dos afetos; e) a conduta cognitiva é uma conduta interessada: sua natureza apreciativa e valorativa está ancorada, em última instância, na economia de nossos desejos" (SCHAEFFER, 2002, p. 26-30). ${ }^{8}$
\end{abstract}

O sujeito que está em relação no cotidiano é produzido no ato de afetar e ser afetado pelo outro através de materiais significantes, com os quais lida diariamente. Ele está constantemente susceptível ao acontecimento e ao imprevisível. O interesse aqui é entender o cotidiano como palco de oscilações, dimensão da vida que se marca pela experiência. Como espaço de dimensões objetivas e subjetivas, o cotidiano é lugar da constituição dos laços e da sociabilidade, tornando-se palco de uma teatralidade com cenas, atores e enredos que se repetem e se renovam (GUIMARÃES, 2006). Ou seja, o cotidiano já está preparado para receber as intervenções artísticas, conservando-se como forma capaz de articular o estar em um mundo aberto, em fluxo, permanentemente construído no entremear de imagens, falas, tradições e saberes. Nesse contexto, o grupo Udflugt também 
Revista da Associação Nacional dos

Programas de Pós-Graduação em Comunicação

\section{(e) compós}

www.compos.org.br

está em sintonia com a idéia de que a experiência cotidiana ultrapassa a mera representação de papéis e permite o movimento e a intervenção dos sujeitos.

A sociologia romântica se opõe à postura determinista da sociologia positivista para abordar o cotidiano. Podemos dizer que a sociologia poética trabalha a emoção, a vida que vemos, tocamos e sentimos sem partir para uma decodificação do real para validar a significação atribuída aos fatos. Uma sociologia que evidencia o cotidiano, o simbólico, o imediato, o local. Esta sociologia, proposta por Michel Maffesoli, sugere a globalidade no interior do fragmento, a integração dentro do objeto de pesquisa, o fato de estar junto como participante. Com esta perspectiva poética da sociologia podemos analisar, com maior rigor e menor rigidez, o cotidiano da cidade com seus fluxos e refluxos de signos, códigos, mensagens e relatos.

\section{Apropriações e deslocamentos: Duchamp como inspiração}

A proposta de apropriação do espaço urbano se aproxima com a proposta de Duchamp, que deslocou objetos do cotidiano para o espaço artístico. Duchamp antecipou o esgotamento do dilema entre figurativo vs. não figurativo, dentro e fora do espaço artístico, assim como levou o questionamento dos suportes das artes até o limite da dissolvência. Em suas intrigantes contravenções, ele estava evidenciando de forma irônica que, assim como qualquer imagem tem caráter de signo por ser uma forma de representação, qualquer objeto também tem uma natureza sígnica ou quase-sígnica que lhe é própria, ditada por sua funcionalidade. Do mesmo modo que uma palavra muda de sentido quando deslocada de um contexto para o outro, também os objetos encontram a consumação de seus significados em seus usos, sempre contextuais. Duchamp então começou a colocar no museu partes de objetos encontrados na rua: roda de bicicleta, porta-garrafas, vaso sanitário. A partir disso, o artista se viu liberado para sua "proposta de reintegração da arte com a matéria vertente da vida” (SANTAELLA, 2004, p. 144). A influência de Duchamp foi crucial em todas as manifestações da arte que se seguiram, na sua busca de fusão com a vida.

Segundo José Bragança de Miranda (1998, p.182), estes exercícios realizados na fronteira entre arte e vida, recriam o espaço da eternidade atual da obra de arte, tendendo a 
Revista da Associação Nacional dos

Programas de Pós-Graduação em Comunicação

\section{(e) compós}

www.compos.org.br

disseminar os procedimentos estéticos na totalidade da existência. A sua insistência na vida funciona como um operador de disseminação do estético na experiência. O autor afirma que a diferença entre arte e vida é abolida, fazendo entrar a vida na arte, e não a arte na vida. Mas a partir do momento em que as performances e intervenções passam a fazer parte do espaço cotidiano, observa-se uma renegociação desta prática, que passa a propor a inserção da arte no movimento urbano, de uma maneira ainda mais viva e processual.

Com seus readymades, Duchamp quis mostrar que o artista não inventa nada, mas que somente usa, manipula, desloca, reformula e reposiciona o que a história fornece. Os readymades propõem que o artista não pode fazer, mas pode somente levar o que já está aí. Assim como os readymades de Duchamp, as site-specific performances também propõem este deslocamento. Mas, neste caso, o deslocamento é do próprio espaço artístico para o espaço urbano, além, é claro, do deslocamento do espectador através deste espaço, aberto a diferentes leituras e percepções, a partir de estratégias de um trabalho artístico fenomenológico. Assim como o espaço da galeria pode transformar o significado de um objeto banal do cotidiano, a própria cidade pode se transformar diante dos olhos do espectador. Aqui pode ser colocada a seguinte questão: como um trabalho define um espaço e como um espaço define um trabalho?

\section{A percepção, a recepção e o ritual}

Walter Benjamin já havia observado que “no interior de grandes períodos históricos, a forma de percepção das coletividades humanas se transforma ao mesmo tempo que seu modo de existência. O modo pelo qual se organiza a percepção humana, o meio em que ela se dá, não é apenas condicionado naturalmente, mas também historicamente”(BENJAMIN, 1985, p. 169).

Para o autor, as transformações da faculdade perceptiva na modernidade poderiam ser compreendidas segundo a ótica do declínio da aura, que seria uma figura singular, composta de elementos espaciais e temporais. "Observar, em repouso, numa tarde de verão, uma cadeia de montanhas no horizonte, ou um galho, que projeta sua sombra sobre nós, significa respirar a aura dessas montanhas, desse galho” (Idem, p.170). Para reforçar seu conceito de aura, Benjamin destacou o aqui e o agora da obra de arte, que se constitui 
Revista da Associação Nacional dos

Programas de Pós-Graduação em Comunicação

\section{e compós}

www.compos.org.br

como uma experiência individual, tornando-se única para quem a vivencia. Partindo desse princípio, como Benjamin veria as propostas de performances, experiências e intervenções urbanas contemporâneas, que fazem com que o espectador vivencie no próprio espaço urbano uma experiência artística? O autor veria estas experiências como uma migração da “aura” para o espaço urbano, a partir do momento em que ele é percebido de outra forma?

É pertinente também deslocar o conceito de ritual, trabalhado por Benjamin a partir de uma perspectiva moderna da produção do espaço e da experiência artística. Benjamin apontou que no início as obras de arte surgiram a serviço de um ritual mágico e, posteriormente, de um ritual religioso. Quando a técnica de reprodução instaurou a doutrina da arte pela arte, sua função social começa a se destacar. Convém então perguntar se esse conceito de aura e o próprio conceito de ritual não seriam resgatados pela sitespecific performance no espaço urbano, a partir do momento em que cada experiência é única, pessoal e individual e acontece no momento de encontro do espectador com a situação perceptiva. Nesse caso ele vivencia o aqui e o agora da obra, que não se separa do seu valor ritual e sua “exposição” acontece no momento da experimentação.

Outro ponto relevante é a observação de Benjamin sobre a influência das transformações sociais nas mudanças na estrutura da recepção, que são apropriadas pelas novas formas de arte. No caso das site-specific performances, isso se torna evidente dentro do processo contemporâneo de convergências e hibridizações, que também fazem com que os espaços sejam apropriados e experimentados de diferentes formas, a partir de propostas artísticas, culturais e sociais.

\section{A Lapa e sua ocupação pelo grupo Udflugt}

Nos lugares que se tornam pontos que unem as pessoas que ali circulam, as emoções partilhadas e consolidadas são vividas como fatos constituídos por e para os grupos que os ocupam. Tais lugares, denominados de "hauts lieux" por Maffesoli, são consolidados em diferentes tempos por “espíritos” diversos que deixam suas marcas. Cada cidade apresenta seus próprios "hauts lieux”, que emanam uma aura especial, chamando a atenção de todos. A Lapa, com seu imaginário de festa permanente, chamou a atenção do grupo Udflugt, que escolheu o bairro para suas experiências e intervenções performáticas. 
Revista da Associação Nacional dos

Programas de Pós-Graduação em Comunicação

\section{(e) compós}

www.compos.org.br

Durante um mês o grupo se estabeleceu em um estúdio da Rua da Lapa, alternando suas atividades com as aulas de samba que acontecem no lugar, que também funciona à noite como um clube de dança. Ao invés de se concentrar no aspecto boêmio explícito da Lapa, o Udflugt procurou percorrer suas ruelas, convivendo nos espaços de sociabilidade dos próprios moradores e freqüentadores do local no seu dia a dia.

Em seu método de trabalho, o grupo procura descobrir diferentes maneiras de se mover em uma área, para descobrir as singularidades que constroem efetivamente a sua “alma”. Entre as práticas sugeridas estão: seguir as pessoas em seus movimentos rotineiros; ultrapassar a fronteira da porta e entrar efetivamente em lugares que atraem a atenção; criar percursos em um mapa e segui-los com precisão; criar diferentes trajetórias entre os mesmos pontos, estabelecendo o caminho mais fácil, ou o caminho mais interessante, ou o caminho mais natural.

Após este mapeamento perceptivo do local, o grupo já começa seu processo de criação e intervenção performática, buscando abrir diferentes perspectivas e aumentar a sensação de presença e a sensibilidade do espectador que passará pela experiência. Entre as ações que guiam este processo criativo estão: intensificar e excluir sentidos, ativando e desativando cheiro, tato, visão, audição, etc.; posicionar os espectadores em situações diferentes e inusitadas; criar textos, sugestões e questões que proponham diferentes percepções; estabelecer a conexão entre sons, imagens e lugares. Neste processo, o fundamental é pensar no ponto de vista e na experiência do espectador e no que pode ser interessante e desafiador para ele, a partir do momento em que ele se encontra em determinado lugar. Quais os tipos de experiências o espectador pode vivenciar, fazendo-o descobrir este lugar através de percepções diferenciadas, ultrapassando os limites da superfície? O que pode provocar outra sensação de presença, outra conexão entre corpo e mente do espectador e corpo e mente da cidade? Que viagem performática proporcionará outro tipo de relação com os elementos urbanos, mesmo que de forma efêmera, mas que deixe resíduos da experiência? Estas são algumas das questões que o grupo coloca e que servem como guia para seus experimentos no espaço urbano. 
Revista da Associação Nacional dos

Programas de Pós-Graduação em Comunicação

\section{e compós}

www.compos.org.br

\section{O espaço, a sociabilidade $e$ a intervenção}

O que surpreendeu o grupo Udflugt no Rio de Janeiro, mais especificamente na Lapa, foi, justamente, a reação dos moradores do lugar e a forma como eles interagiram com os espectadores e os performers. Este aspecto social foi certamente um grande ganho para o grupo, acostumado com o cotidiano e com as formas de sociabilidade européias.

Michel Maffesoli ${ }^{9}$ afirma que a sinergia entre o espaço e a sociabilidade cria um mundo original a partir da relação que a pessoa estabelece com o outro. Este mundo está em permanente formação e se constitui em um conjunto de referências partilhadas. $\mathrm{O}$ autor acentua a importância do mundano na formação de nossas sociedades, a grandeza e o trágico contidos no cotidiano e propõe uma intensiva aproximação com o objeto de pesquisa - o espaço urbano - sempre em movimento. Ocupamos um espaço material, constituído por ruas, monumentos e trânsito, ao mesmo tempo em que constituímos o espaço imaterial a partir das imagens de diversas ordens. Nestes dois pontos a ordem do simbólico é criada, a partir da circulação das informações, das coisas, das palavras e de tudo aquilo que faz parte de processos comunicativos e de sociabilidades.Ver e analisar de forma distanciada os fatos que constituem o social, não é suficiente. Metodologicamente, Maffesoli revela o aspecto tátil cada vez mais necessário na construção de qualquer objeto de pesquisa na sociedade contemporânea.

Esta aproximação também é proposta pelos grupos artísticos que desenvolvem seus trabalhos em meio aos fenômenos urbanos. E suas inserções nas dinâmicas cotidianas das cidades proporcionam um diálogo e uma contaminação contínua, que fazem da experiência algo em constante construção.

Quando Maffesoli diz que o mundo é um conjunto de referências que eu partilho com outros, está valorizando a força da sociabilidade no processo de costura das redes de solidariedade, que solidificam as estruturas culturais. Estas estruturas de conjunto são compostas hoje pelo sensível, que por muito tempo foi negligenciado, reaparecendo de maneira intensa no cotidiano da vida social. No interior das formações sociais cotidianas podemos vislumbrar criações de familiaridades específicas que valorizam a experiência do aqui e agora (MAIA, 2005). Ao conviver com os grupos e famílias que estão nos bastidores do cenário boêmio da Lapa, o grupo Udflugt pôde vislumbrar este fenômeno e, a 
Revista da Associação Nacional dos

Programas de Pós-Graduação em Comunicação

\section{(e) compós}

partir daí, criar suas intervenções sem se chocar com o cotidiano destas pessoas. O trabalho passou a ter então um forte aspecto social, que ainda não havia sido explorado em suas intervenções nas cidades européias.

\section{Um recorte geográfico}

Milton Santos fala de objetos e ações. A interação entre sistemas de objetos e sistemas de ações faz com que o espaço encontre a sua dinâmica e se transforme, através das condições que ele mesmo oferece para a produção, para a circulação, para a residência, para a comunicação, para o exercício da política, para o exercício das crenças, para o lazer, para o "viver bem” (SANTOS, 2001, p.55).

Como meio operacional, o espaço se oferece para uma avaliação objetiva, ou funcional e como meio percebido está subordinado a uma avaliação subjetiva, ou resultado de diferentes percepções. Porém um mesmo espaço pode ser visto como o terreno das operações individuais e coletivas, ou como realidade percebida, havendo invasões recíprocas entre elas. O espaço geográfico é constituído pelas ações que ele pode acolher e deve ser considerado como algo que participa igualmente da condição do social e do físico. Sua natureza híbrida se acentua cada vez mais, principalmente quando o espaço observado é o espaço da metrópole contemporânea.

Pela perspectiva geográfica, Milton Santos considerou o espaço como um conjunto de fixos e fluxos. Os elementos fixos permitem ações que modificam o próprio lugar. Já os fluxos novos ou renovados são um resultado direto ou indireto das ações, atravessando ou se instalando nos fixos, modificando a sua significação e o seu valor, ao mesmo tempo em que também se modificam. Segundo o autor, os fluxos são cada vez mais diversos, mais amplos, mais numerosos e mais rápidos. A partir dessa perspectiva, as intervenções urbanas e performances podem ser consideradas fluxos efêmeros, que passam, alteram o ambiente, a percepção dos objetos e as sociabilidades, oferecendo uma experiência artística, mas que dificilmente vão mudar a constituição destes espaços.

Segundo Paulo Godoy (2004), a noção de “(des)construção” do espaço baseia-se na concepção de que a sociedade pós-moderna, ao mesmo tempo em que produz formas 
Revista da Associação Nacional dos

Programas de Pós-Graduação em Comunicação

\section{e compós}

www.compos.org.br

espaciais que atendem à necessidades de produção, circulação, consumo e informação, também as dissolvem e as redefinem em sintonia com as novas necessidades sociais.

A presença do humanismo na geografia contribuiu para estabelecer, como referência, o espaço vivido, construído socialmente a partir da percepção. Os conceitos de lugar e paisagem, passaram a apresentar-se como foco de ação emocional do homem e uma fonte de significados. Para Paulo Godoy, a “(des)construção” da paisagem se dá pela mudança do significado simbólico das formas e pelo modo como elas afetam os valores culturais e os mecanismos cognitivos de percepção da paisagem “(des)construída”. Quando localizamos as intervenções performáticas urbanas neste contexto, percebemos como algumas delas podem evidenciar este fenômeno de “(des)construção”, apresentando-se como recortes espaço/temporais que possibilitam uma mudança efêmera do significado das formas e um estímulo aos mecanismos cognitivos, que podem deixar resíduos e afetar os valores culturais. Harvey já apontava que uma das missões do modernismo era "a produção de novos sentidos para o espaço e o tempo num mundo de efemeridade e fragmentação" (1994, p.199).

\section{O vocabulário da cidade e a leitura simbólica}

Em sua análise sobre os fenômenos urbanos, Lefebvre (2003) identifica dois importantes aspectos: dimensões e níveis. Segundo o autor, eles nos ajudam a ordenar algumas das discussões sobre a cidade e questões urbanas, discussões que misturam textos e contextos, níveis e dimensões. Tais aspectos podem estabelecer um vocabulário e uma escrita da cidade e de seus elementos palpáveis e visíveis, que possibilitam a sua leitura. As leituras possíveis são variadas e podem ser feitas a partir de perspectivas geográficas, econômicas, sociológicas, antropológicas, comunicacionais, estéticas, etc. Para Lefebvre, organizar fatos usando conceitos não exclui outras formas de discursos, classificações, leituras ou seqüências (geopolíticas, organizacionais e administrativas, tecnológicas, etc.). Este aspecto convergente já está inserido no próprio processo de análise dos fenômenos urbanos.

Lefebvre identificou três níveis - o global, o misto e o privado. Poderíamos dizer que as atuações do grupo Udflugt se encontram no nível misto, sem deixar de exercer 
Revista da Associação Nacional dos

Programas de Pós-Graduação em Comunicação

\section{(e) compós}

www.compos.org.br

alguma influência nos outros níveis, já que ele é resultado deste meio, o ponto de transição, de comunicação e exteriorização. O nível misto se encontra no intermediário e é especificamente o cenário de trocas urbanas, com suas ruas, praças, avenidas, prédios públicos, igrejas, escolas, etc., e ocupados pelos homens e mulheres que convivem na cidade. O que permanece é a relação com o lugar e com as situações possíveis neste lugar. O autor também se refere ao nível “sócio-lógico”, no qual cada objeto se comunica com cada ação e sistema de significações. Cada objeto contamina cada ação, porém um lugar nunca apresenta uma única lógica, pois sempre existirão lacunas, resíduos e conflitos.

Segundo Lefebvre, os fenômenos urbanos e o espaço urbano não são somente uma projeção das relações sociais, mas o lugar onde estratégias se confrontam. A realidade e a vitalidade de um lugar são explicitadas nas práticas urbanas que se formam independente das ideologias globais ou institucionais, envolvendo o espaço e sua organização. É tudo aquilo que se constrói à parte de objetivos lógicos e previamente planejados. É o aspecto orgânico das relações sociais e os usos do espaço que exteriorizam suas dimensões simbólicas. David Harvey também vai para o mesmo caminho e afirma, em seu conceito chave, que o tempo e espaço não podem ser compreendidos independentemente da ação social.

Convém aqui explorar um pouco mais as três dimensões do espaço, desenvolvidas por Lefebvre, para compreender um pouco mais as relações entre os espaços e suas práticas. A primeira dimensão que o autor aponta é a material, que se refere aos fluxos, transferências e interações físicas e materiais que se dão no espaço, garantindo a produção e a reprodução social. A segunda dimensão diz respeito às representações do espaço, compreendendo signos, significações, códigos e conhecimentos que permitem falar sobre essas práticas materiais e compreendê-las. A terceira dimensão coloca os espaços de representação como "invenções mentais, que imaginam novos sentidos ou possibilidades para práticas espaciais” (HARVEY, 1994, p.201).

Mesmo sem conhecer as dimensões do espaço propostas por Lefebvre, o grupo Udflugt procura realizar um mapeamento de vários aspectos do lugar onde vai atuar, para evitar uma leitura empobrecida, que privilegie apenas os elementos que estão na superfície, ou que são historicamente estabelecidos e aceitos. Esse momento de pesquisa e 
Revista da Associação Nacional dos

Programas de Pós-Graduação em Comunicação

\section{(e) compós}

www.compos.org.br

“diagnóstico" do espaço é fundamental no seu processo, pois o grupo acredita que precisa estar em sintonia com as tendências contemporâneas de apreensão dos fenômenos urbanos. É essa consciência que possibilita o surgimento de performances que efetivamente levam a uma percepção diferenciada do entorno, ao mesmo tempo em que são inseridas com uma quase naturalidade, utilizando elementos do próprio local.

\section{Notas}

1 Mestranda do Programa de Pós Graduação e Cultura da ECO/UFRJ. Email: infernanda@yahoo.com.

${ }^{2}$ Informações obtidas durante o workshop do Grupo Udflugt, entrevistas com a performer Vera Maeder e no site www.udflugt.com

${ }^{3}$ Eero-Tapio Vuori é diretor de teatro e eventos performáticos. Atualmente está à frente do "Reality Research Center” em Helsinki, Finlândia.

${ }^{4}$ Como participante da oficina, pude acompanhar todo o processo de pesquisa, criação e desenvolvimento desta site-specific art no Rio de Janeiro.

${ }^{5}$ Disponível em: www.todellisuudentutkimuskeskus.net

${ }^{6}$ Durante o workshop do Grupo Udflugt os participantes tiveram a oportunidade de experimentar essa proposta. Por uma hora permaneceram sentadas de frente para uma das ruas da Lapa, apenas observando o espaço e os movimentos cotidianos daquele lugar. Após alguns minutos, a rua passa a ser observada como se fosse um palco, repleto de pequenos acontecimentos intrigantes.

${ }^{7}$ Manifesto de Victor Shklovsky,1917.

${ }^{8}$ In GUIMARÃES, César G.; FRANÇA, Vera R.V. (orgs.). Na mídia, na rua. Belo Horizonte: Ed.Autêntica: 2006, p. 98 e 99.

9 In MAIA, João. Michel Maffesoli e a cidade partilhada. Revista FAMECOS. Porto Alegre, no. 26, 2005.

\section{Referências bibliográficas}

BENJAMIN, Walter. A obra de arte na era de sua reprodutibilidade técnica. IN: Walter Benjamin: obras escolhidas. São Paulo: Brasiliense, 1996. p. 165-196.

BERGUER, P. e LUCKMANN, T. A construção social da realidade. Petrópolis: Vozes, 1985.

CERTEAU, Michael de. A invenção do cotidiano: artes de fazer. Petrópolis: Vozes, 1997.

DELEUZE, Gilles. Entrevista sobre Mille Plateux. IN: Conversações. São Paulo: Editora 34, 1992. 
Revista da Associação Nacional dos

Programas de Pós-Graduação em Comunicação

GODOY, Paulo. Uma reflexão sobre a produção do espaço. Estudos Geográficos. Rio Claro, 2 (1): 29-42, jun. 2004.

GUIMARÃES, César G.; FRANÇA, Vera R.V. (orgs.). Na mídia, na rua. Belo Horizonte: Ed.Autêntica: 2006.

HARVEY, David. Parte III: A experiência do espaço e do tempo. IN: Condição pós-moderna: uma pesquisa sobre as origens da mudança cultural. São Paulo: Loyola, 1994.

KAYE, Nick. Site-specific art. Performance, place and documentation. USA: Routledge, 2000

LEFEBVRE, Henri. Levels and dimentions. IN: STUART ELDEN, Elizabeth Lebas; KOFMAN, Eleonore(eds.). Henri Lefebvre Key Writings. New York, London: Continuum, 2003.

MAIA, João. Michel Maffesoli e a cidade partilhada. Revista FAMECOS. Porto Alegre, no. 26, 2005.

MIRANDA, José Bragança. Da Interactividade. Crítica da nova mimesis tecnológica. In: GIANNETTI, Claudia (org). Ars Telemática - Telecomunicação, Internet e Ciberespaço. Lisboa: Relógio d’Água, 1998.

SANTAELLA Lucia. Culturas e artes do pós-humano: da cultura das mídias a cibercultura. São Paulo: Paulus, 2004.

SANTOS, Milton. Uma ontologia do Espaço: noções fundadoras. IN: A natureza do Espaço. São Paulo: Edusp, 2001. 